Supplement of Atmos. Chem. Phys., 21, 4007-4023, 2021

https://doi.org/10.5194/acp-21-4007-2021-supplement

(C) Author(s) 2021. CC BY 4.0 License.

(c) (i)

Supplement of

\title{
A comparison of long-term trends in observations and emission inventories of $\mathrm{NO}_{x}$
}

Elena Macdonald et al.

Correspondence to: Tim Butler (tim.butler@iass-potsdam.de)

The copyright of individual parts of the supplement might differ from the article licence. 


\section{S1 Data and Methods}

Table S1. Reference list of all R packages that were used.

\begin{tabular}{lll}
\hline Package & Author(s) & Year \\
\hline devtools & H. Wickham, J. Hester, W. Chang & 2020 \\
dplyr & H. Wickham, R. Francois, L. Henry, K. Müller & 2020 \\
egg & B. Auguie & 2019 \\
forcats & H. Wickham & 2020 \\
geosphere & R. J. Hijmans & 2019 \\
ggnewscale & E. Campitelli & 2020 \\
ggplot2 & H. Wickham & 2016 \\
ggpubr & A. Kassambara & 2020 \\
ggrepel & K. Slowikowski & 2020 \\
gridExtra & B. Auguie & 2017 \\
lubridate & G. Grolemund, H. Wickham & 2011 \\
maptools & R. Bivand, N. Lewin-Koh & 2019 \\
matrixStats & H. Bengtsson & 2020 \\
openair & D. C. Carslaw, K. Ropkins & 2012 \\
rgdal & R. Bivand, T. Keitt, B. Rowlingson & 2019 \\
rgeos & R. Bivand, C. Rundell & 2019 \\
rlang & L. Henry, H. Wickham & 2020 \\
segmented & V. M. R. Muggeo & 2008 \\
stringr & H. Wickham & 2019 \\
tibble & K. Müller, H. Wickham & 2020 \\
tidyr & H. Wickham, L. Henry & 2020 \\
viridis & S. Garnier & 2018 \\
\hline & &
\end{tabular}


Table S2. Data sources of the city shapefiles that were used for retrieving the corresponding gridcells from the EMEP grid. All shapefiles were downloaded in January 2020.

\begin{tabular}{ll}
\hline City & URL \\
\hline Amsterdam & https://maps.amsterdam.nl/open_geodata/?k=202 \\
Augsburg & https://www.arcgis.com/home/item.html?id=ae25571c60d94ce5b7fcbf74e27c00e0 \\
Berlin & https://esri-de-content.maps.arcgis.com/home/item.html?id=9ae4f23075d340adb6580a6d9603f9fa \\
Geneva & https://opendata.swiss/de/dataset/swissboundaries3d-bezirksgrenzen \\
Linz & https://www.data.gv.at/katalog/dataset/bezirksstadtabgrenzung/resource/1aa22b8d-ef5f-4c66-be62-9bb5045bf1de \\
London & https://data.london.gov.uk/dataset/inner-and-outer-london-boundaries-london-plan-consultation-2009 \\
Prague & https://data.gov.cz/datov\%C3\%A1-sada?iri=https\%3A\%2F\%2Fdata.gov.cz\%2Fzdroj\%2Fdatov\%C3\%A9-sady\% \\
& 2Fhttp---atom.cuzk.cz-api-3-action-package_show-id-cz-00025712-cuzk_ruian-obce-shp_554782 \\
Vienna & https://www.data.gv.at/katalog/dataset/stadt-wien_bezirksgrenzenwien \\
Zurich & https://data.stadt-zuerich.ch/dataset?q=grenzen \\
\hline
\end{tabular}

Table S3. Sources and availability of data sets on wind directions and wind speed for seven cities. DWD - Deutscher Wetterdienst (German Weather Service); CHMU - Český hydrometeorologický ústav (Czech Hydrometeorological Institute); ZAMG - Zentralanstalt für Meteorologie und Geodynamik (Central Institution for Meteorology and Geodynamics).

\begin{tabular}{lllcc}
\hline City & Source & Station & Temp. Res. & Timeframe \\
\hline Augsburg (DE) & DWD: Climate Data Center & Augsburg 00232 & hourly & $1998-2017$ \\
Berlin (DE) & DWD: Climate Data Center & Berlin-Tempelhof 00433 & hourly & $1997-2017$ \\
Geneva (CH) & MeteoSchweiz: IDAWEB & Geneva Cointrin GVE & hourly & $1991-2017$ \\
London (GB) & Met Office (e-mail) & London Heathrow & hourly & $2008-2017$ \\
Prague (CZ) & CHMU (e-mail) & Praha-Klementinum & 7am, 2+9pm & $2012-2017$ \\
Vienna (AT) & ZAMG: Jahrbuch & Wien Hohe Warte & 7am, 2+7pm & $1992-2017$ \\
Zurich (CH) & MeteoSchweiz: IDAWEB & Zurich Affoltern REH & hourly & $1992-2017$ \\
\hline
\end{tabular}


S2 Absolute Emissions and Increments

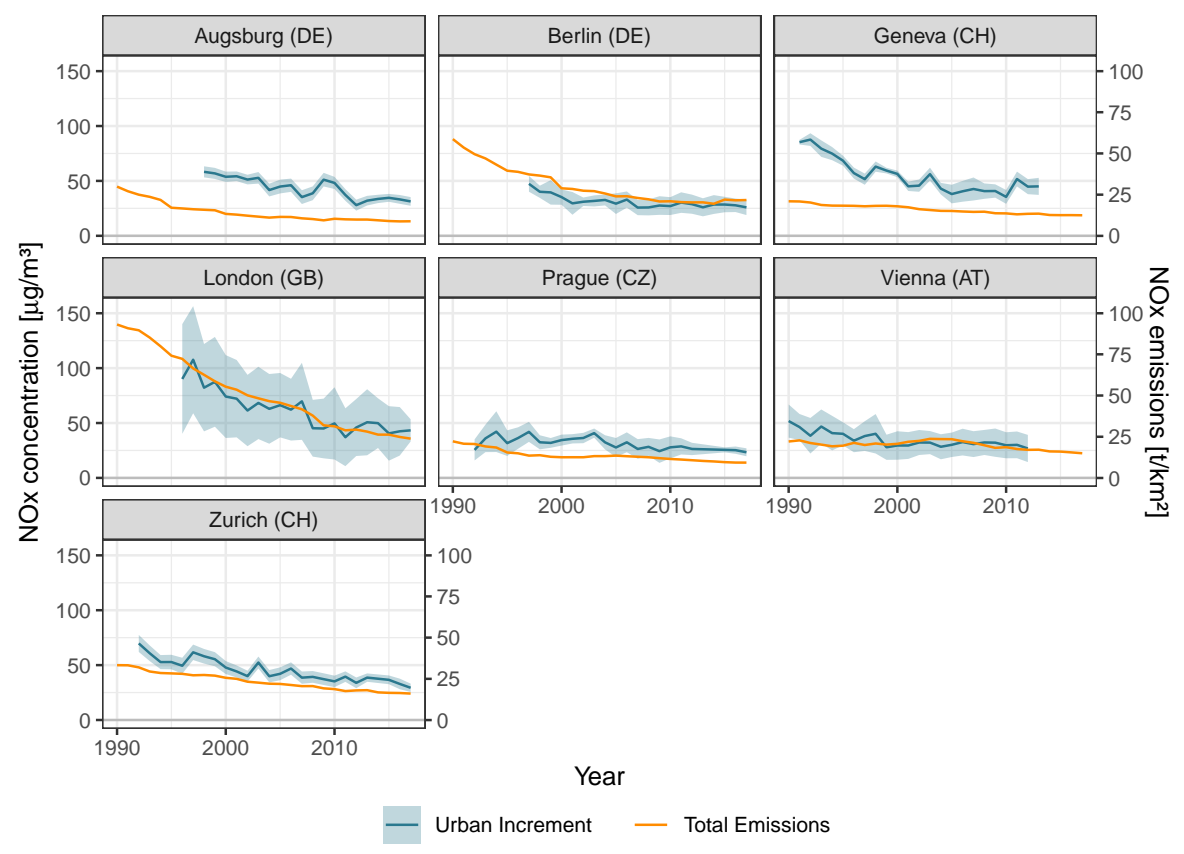

Figure S1. Urban increments (UIs) and total emissions of $\mathrm{NO}_{\mathrm{x}}$ for seven European cities. The UIs are derived from rural and urban background monitoring stations; emissions are averaged for the urban areas based on the EMEP emissions grid. Shaded areas represent one standard deviation. Note the different scales for emissions and UIs. 

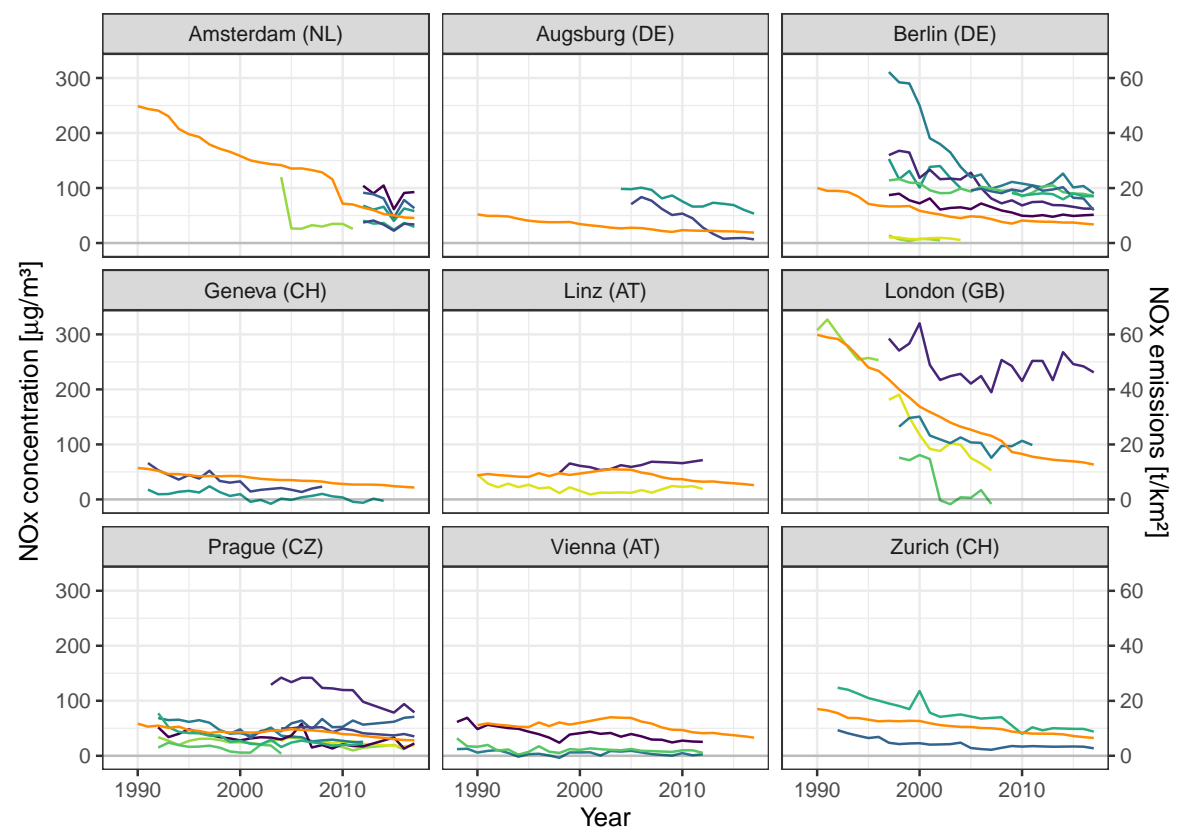

Figure S2. Roadside increments (RIs) and traffic emissions of $\mathrm{NO}_{\mathrm{x}}$ for nine European cities. The orange lines represent traffic emissions and these are averaged for the urban areas based on the EMEP emissions grid. All other lines depict individual RIs which are each specific to a certain urban traffic monitoring station. Note the different scales for emissions and RIs. 